\title{
Establishing the Contexts of Disruptive Behaviours and Psychological Implications among Pre-Primary and Primary School Pupils
}

\author{
Janet Ngozi Igbo ${ }^{1}$, Angie Oboegbulem ${ }^{2}$ \& Ifeyinwa Ezenwaji ${ }^{3}$ \\ ${ }^{1}$ University of Nigeria, Nsukka/Department of Educational Foundations, Nigeria \\ ${ }^{2}$ University of Nigeria, Nsukka/Department of Educational Foundations, Nigeria \\ ${ }^{3}$ University of Nigeria, Nsukka/Department of Educational Foundations, Nigeria \\ Correspondence: Janet Ngozi Igbo, University of Nigeria, Nsukka/Department of Educational Foundations, \\ Nigeria. E-mail: janetigbo@yahoo.com
}

Received: August 27, 2017

Accepted: September 5, $2017 \quad$ Online Published: November 21, 2017

doi:10.5539/res.v9n4p114

URL: http://doi.org/10.5539/res.v9n4p114

\begin{abstract}
The study attempted to examine the contexts under which disruptive behaviors occur among pupils in pre-primary and primary schools in Nsukka Urban. The population of the study comprised all pre-primary and schools pupils. A sample of one hundred and sixty-four (164) pupils (both male and female) was drawn. Data was collected through observation. The mean was adopted for answering the research questions. The findings indicated that the context under which disruptive behaviors were displayed by pupils, include the following: when child lacks writing materials, when the environment is noisy, when the child is oppressed by his or her classmates, when the child is frustrated and when the child lacks adequate communication. The findings also indicated that with male pupils, disruptive behaviors occur frequently under all the five items, while with the female pupils disruptive behaviors occur frequently under four of the items and occur slightly on one the items. The psychological implications were also addressed in the study.
\end{abstract}

Keywords: behavior, disruptive behaviors, context, learning, academic achievement

\section{Introduction}

\subsection{An Overview of the Study}

Behavior is seen as objectively or publicly observable responses. It includes such conscious phenomena like thinking, perceiving and judgment (Ramalingam, 2006). This implies that behavior has to do with the individual's personal conduct, actions, comportment deportment and bearing. Disruptive behavior is one of the ways children test the environment, while attempting to assert their independence. Hurlock (1982), Ali and Gracey (2013) argues that fighting and punching are part of the normal exploratory methods children use in social behavior. The young child who has not yet learned to socialize gives vent to disruptive behavior while struggling with environmental demands.

Disruptive behavior is a disability in which children consistently show one or more of the following characteristics over a period of time: inactivity, hyperactivity, and impulsivity (Nelson, 2011; Ofordile, 2002). This group of children has difficulty in concentrating on anything and easily become bored with a task, after a few minutes. Disruptive children show high levels of physical activity, always in motion, have difficulty in curbing their reactions and have problem of acting before thinking.

Signs of disruptive behavior are often present in pre-primary schools. The increased academic and social demands of formal schooling, as well as standards for behaviors are required from children are not usually met (Dunn \& Hughes, 2001). Teachers report that these types of children have difficulty in working independently and also lack organization. Restlessness and distractibility also are often noted. Pupils learn disruptive behaviors in just the same way they learn other forms of behaviors. Galloway (1982), Ikediasi and Akande (2015) defined disruptive behavior as any behavior which appears problematic, inappropriate and disturbing to the teachers. Such behaviors manifest themselves in different contexts.

Disruptive behavior can be manifested when the child lacks writing materials. When the environment is noisy, when the child is frustrated. According to Lindgren (1976), disruptive behavior is a matter of concern for teachers 
because they are likely to interfere with learning. These behaviors have been the focus of a great deal of the research on children's disorders probably because children with these disorders are quite difficult to deal with, and these behaviors can exact a heavy toll on society (Nelson, 2011; Ajibola \& Ali, 2014).

Children that manifest disruptive behavior are seen as those who found to lag behind in comparison to the peers of their ages with respect to mental. Social, emotional and moral characteristics (Mangal, 2010). These have to do with significant deficiencies and incapability in relations to the personality of these children concerned. Usually disruptive children may be labeled as delinquents, emotionally and socially disturbed children and culturally deprived children as the case may be. In line with this Davey (2011) who noted that disruptive behavior are characterized by impulsive, disruptive and poorly controlled behavior. It is the inability of children to restrain them from certain unwanted behaviors. This implies that children at this stage are unable to control their behaviors, attend to tasks in the classroom situation, and refusal to follow appropriate instructions. These attitudes lead to the manifestation of disruption of activities which can affect the academic performance and achievement of this group of children. Some studies noted that disruptive behaviors manifest in different contexts across different cultures and ethnic groups (Rosenbery, 2005; Balley \& Owens, 2005; Ali \& Gracey, 2013). This actually depends on different environmental factors based on culture.

Disruptive behaviors are therefore seen as those behaviors that are unwanted and unwarranted during teaching and learning activities in pre-primary and primary schools. These behaviors not only interfere with the classroom activities but consume both energy and time. In other words, disruptive behavior is behavior that deviates from the organizational rules and regulations of a particular school. For instance a child that walks about in the classroom during writing activity is said to be a disruptive child because the child has deviated from the standard expectations and from what other members are doing.

Disruptive behaviors are very common in educational institutions, particularly pre-primary and primary schools. Besides, what constitutes disruptive behavior differs according to the standard expectation of a particular level of education. In the pre-primary and primary school levels, behavior accepted as disruptive behavior in secondary schools may not be recognized as disruptive behavior in the tertiary institutions. Behaviors are disruptive in as much as they interfere with teaching and the teacher's state of mind in the normal running of both the classroom lesson and out-door activities. Again, disruptive behaviors interfere with the learning activities of not only the disruptive child but other children in the classroom. The child whose behavior is disruptive reacts to the school situation with hostility, suspicion, reluctance and frustration. Schostak (1983), Rosenberg (2005) and Edovald (2001) draw on the testimony of pupils to make the case that disruptive behavior in schools can often be seen as a rational response to intolerable conditions. All disruptive behaviors, no matter what factors may be responsible for them, seem to emanate from a basic sense of inadequacy and helplessness, in the face of over-powering forces, which the individual feels he cannot control. Disruptive behaviors usually take place in normal classroom situations. They are also very common during practical science and domestic science classes, when the environment is noisy, when the child is frustrated and oppressed by other classmates, when the child lacks communications, and when the child lacks materials for learning.

In both pre-primary and primary schools in Nigeria, including Nsukka, disruptive behaviors have become a major source of concern to school administrators, teachers, psychologists, and parents alike. Disruptive behaviors such as fighting, talking, crying, running and jumping interfere with normal classroom activities and divert attention to the acting pupils and the problem behavior. Behaviors are disruptive as far as they interfere with or interrupt the process of teaching and learning in the classroom and organized out-door activities. What constitutes the context of disruptive behavior may differ according to the standard expectations of a particular level of education-whether pre-primary, primary, secondary or tertiary institutions.

Studies have been carried out on the incidence of disruptive behaviors (Stott 1982), and forms of disruptive behaviors (Davey, 2011). However, not much is known in Nigeria about the contexts in which these disruptive behaviors occur. This is the major objective of this study. Similarly, there is need to try and explain some implications of these behaviors. In line with this Onwuasoanya (2006) found that disruptive behaviors were significantly lower in non-Dutch than Dutch parents and those cultural contexts may have an important influence on the manifestation of disruptive behavior among children.

It is on record that 3-7 percent of school ages between 2-5 years are found to manifest disruptive behaviors within different contexts (Ofordile, 2002). The implication is that if this problem is not controlled by first of all finding the contexts in which these behaviors manifest then the tendency for it to be carried over to adolescence and adulthood stage is not ruled out. This might equally lead to frustration, stubbornness, low self-esteem and depression among others. As noted by Davey (2011) disruptive behavior result to impaired academic achievement, which usually 
leads to conflict with classmates. In line with this Coplan Gauinski-Molins, Lagace-Seguin and Wichman (2001), and Dunn and Hughes (2001) noted that children who persist in immature forms of solitary play such as wandering around aimlessly are at risk of manifesting disruptive behaviors.

\subsection{Theoretical Perspective}

This study was anchored on social learning theory which was propounded by Bandura (1977). It argues that human behavior is developed and maintained through interactional processes. From this view, human behavior is the product of on-going interaction between environmental influences and internal motivations which derive from mainly social experience. This theory acknowledges that children acquire much important behavior by imitating, models in their environment. This implies that the way parents manage disruptive behaviors in the home contribute to children's dispositions to participate in disruptive behaviors and to enact disruption. This is made possible through a learning process which develops by association. When children live in area in which disruptive behaviors is accepted by the play-mates or peer groups, the type of disruptive behavior that they may adopt often relate to that of the play mate; or peer groups. The theory noted that if a child finds himself in good social and cultural environments, his normal development is apparently assured. The social environments of man always expose him to risk. It means that when interaction in a social environment is very poor, the child stands the risk of being a problem to his or her society.

The theory agreed that children are more likely to follow specifically the behavior of other children of their age. This is because generally, they identify with their playmates or peer groups. If the playmates or peers nag, are disruptive, the pupils will behave in a similar manner in other to conform to the playmates or the peers. Here the attitudes and expectations of others are involved. Bandura (1989), emphasized that peers and mates influence a child's standard in terms of his thinking and social behavior. Thus, the behavior of one individual in a class is likely to affect the behavior of others in that class. They reported that the peer group influence children's social development by encouraging them to conform to their own social expectations. By doing this they learn to adjust to peer expectations and to develop patterns of behaviors.

The link is that the desire to play an adequate part in a group of one's own age may be effective in developing disruptive behaviors. Behaviors in group situations whether in negative or positive form, involve being fairly courteous in everyday group association. Certainly, the opinions of their friends are much more important to most of them than are the opinions of their parents. Generally, children accept or develop interests that are unsuitable to their abilities in order to belong to their group. This implies that the sensitive attachment children receive contributes in the development of social skills necessary for social interaction.

\subsection{Review of Related Studies}

Stark (2006) conducted a study on the effects of family conflict on school behavior as perceived by children and Teachers. The study examined the relationship between family conflict and interpersonal difficulties of children in school. The study was designed to ascertain whether students from families with higher levels of conflict exhibited greater interpersonal difficulties than those from families with fewer conflicts. The sample consisted of 96 fourth and fifth grade students in two elementary schools. Result of the study showed that children from families with higher level of conflict. Result of the study showed that children from families with higher levels of conflict exhibited greater behavioral difficulties than children from families with low level of conflicts.

Cooper (1987) study was on "the development and validation of an inventory to detect emotional stress in children". The Emotional Stress Inventory for Children (ESIC) consisting of twenty indicators was designed to detect emotional stress in elementary school children. A panel of experts was asked to rate every child in six elementary grade classes on a seven-point scale stressed and non stressed children were chosen from a sample of 97 children. The result showed that children rate as stressed scored significantly higher on the ESIC than children rate as non-stressed. Ifekwunigwe (2004) conducted a study on "Perceptions of Stress in Elementary School Children". The study examined the relationship between the perception of stress by parents and teachers and the perception of stress by children. The sample consisted of 213 children in middle and upper elementary levels. Questionnaire was used, whereby the children, parents and teachers responded to. Results of the study proved that there are significant difference at the .05 level of significant between the parents' perceptions and the children's perceptions of stress and mental health status. Parents perceived the children as having lower levels of stress than the children perceived themselves. Data analysis proved that the higher the perceived stress level of children the lower their perceived level of well being of anxiety and depression.

Lemieux (1985) conducted a study "The adaptation of Homong first to third graders to the Minneapolis Public School". The study was designed to investigate which variables (psychological), psychosocial stressors, cognitive ability language proficiency or socio-cultural demographic seem to be the best predictors of a Hmong child's 
perceived level of adjustment to the Minneapolis Public Schools. The sample consisted of $52 \mathrm{Hmong}$ first to third graders. Result of the study proved that the child's cognitive ability level was the best predictor of the child's perceived level of the lack of standardization using this measure with non-English speaking children and the significant correlation, between time in country and cognitive ability. Strobel (1986) conducted a study on "The effectiveness of a Parental Training Program for Improving Problematic Behaviors of Children in Regular Classroom". The study was designed to determine the effectiveness of a parental training program for improving the problematic behaviors in children from regular classroom setting in public parochial schools and 38 parent volunteers. The methodology used for the study was a quasi-experimental design, with three treatment groups. The main treatment group consisted of children whose parents received training in: techniques for improving school-related behaviors. Results of the study showed that no improvement was found in observed behavior in the classroom, as a function of treatment.

In another study carried out by Shaffer and Kipp (2007) they observed that preschool children are often unable to understand the chain of events leading from the beginning to the end of stories from watching a TV program. They equally found that 6 years children have problems in recalling a coherent story. These children are more interested in actions rather than stories. The implication is that these children do not fully understand the fictional nature of television rather they see it as actual portrayal of daily activities. The implication of these reviewed studies is that environment is a determinate to the manifestation of disruptive behaviors. These studies are related to the present study because it emphasizes on the contexts in which different behavior problems manifest.

In both pre-primary and primary schools disruptive behaviors have become a major source of concern to school administrators, teachers, psychologists, and parents alike. Disruptive behaviors such as fighting, talking, crying, running and jumping interfere with normal classroom activities and divert attention of both pupils and teachers. Behaviors are disruptive as long as they interfere with or interrupt the process of teaching and learning in the classroom and organized out-door activities. What constitutes disruptive behavior may differ according to the standard and expectations of a particular level of education-whether pre-primary, primary, secondary, or tertiary institutions. A cursory observation across these levels of education indicates that the younger the subjects receiving education, the more disruptive their behaviors during the process of teaching and learning. The increasing incidence of disruptive behaviors in pre-primary and primary schools in Nigeria has become a major source of concern to all who are interested in the education of the young, including teachers, parents and the government. Disruptive behaviors cause many teachers to spend a lot more time and energy sorting out these behaviors than they do on actual teaching. This is an undeniable situation.

As Akubue (1991) and Davey (2011) indicate that teachers spend a good portion of their days dealing with students' behavior problems in secondary schools. If this observation is true of secondary schools with relatively older children (students) the problem can be best imagined with younger children, from three years to eleven years of age, who in addition, bombard teachers with incessant complaints which are often frivolous and mischievous. What is more, many teachers may develop an attitude of indifference toward the activities and complaints of their pupils while some others may become unnecessarily too harsh, abusive and aggressive. In the other hand, parents may create opportunity for disruptive behaviors by not proving learning materials for their children. All these tend to militate against effective teaching and learning in pre-primary and primary schools. Based on these issues, the study attempted to find answers to these research questions:

- What are the contexts under which disruptive behaviors occur among pupils in pre-primary and primary schools?

- What are the contexts under which disruptive behaviors occur among male and female pupils?

\section{Research Method}

In carrying out this study, the researchers applied survey design. According to Ramalingam (2006), Nworgu (2015) and Punch (2011) survey design, is a research technique in which the respondents respond to series of questions. It is a method of socio-psychological research through questionnaires. Survey is conducted for the purpose of establishing opinions, views and personality characteristics of respondents which are what this study was basically interested in. The study was carried out in Nsukka Urban, of Enugu State in Nigeria. Enugu State is located in the South Easter of Nigeria. The state is made up of 17 Local Government Areas. The population for the study was made up of two groups: all disruptive pre-primary and primary school pupils in Nsukka Urban totaling two hundred and fourteen consisting of 109 pre-primary and 105 primary schools pupils.

\subsection{Participants}


One hundred and sixty four children made up of 88 pre-primary and 76 primary school children were selected for this study. The pupils aged between 3 to 5 years and 8 to 10 years for both pre-primary and primary schools respectively. The emphasis on children within these age brackets is that their behaviors are often seen as they are manifested without adult interference. Young children presumably, are less likely than older children or adults to change or manipulate their behaviors in response to being observed. It has been observed that even when young children know that they are being observed they feel less threatened or anxious than adults.

\subsection{Procedure}

The researcher adopted purposive sampling technique because it is appropriate, since it makes provision to select the sample in such a way that there is maximum chance for any relationship to be observed (Punch, 2011; Nworgu, 2015). In sampling the researchers adopted the National Education Association Technique as stated in Krejcie and Morgan (1970) for determining sample size from a given population. As recorded in this technique 1 when the population is between 280 and 290 it attracts sample between 162 and 165 . Therefore, since the population of disruptive children in pre-primary and primary schools within the area of study fall within 289 the sample sizes of 164 for both pre-primary and primary falls within the range of this technique. The major technique for data collection in this study was observation, using checklist of a four-point rating scale. All the children were observed based on the checklist items. The items on the rating scale relate to the context of which disruptive behaviors manifest such as when the environment is noisy, when the child lacks writing materials, when the child lacks communication, when the child is oppressed by his or her classmates and when the child is frustrated. The format for rating and scoring the contexts were as follows: Any disruptive behavior that does not occur throughout the period of observation under the specific contexts was rated "Does not occur" and scored one "I". Any disruptive behavior that occurs 1 to 3 times per week of the period of observation was recorded "occurs slightly" and was scored two "2". Those disruptive behaviors that occur 4 to 6 times per week of the observation were recorded as occurring frequently and scored three " 3 ". On the other hand when such behaviors occur seven " 7 " times and above within the context per week of the observation they were rated "occurs most frequently" and scored four " 4 " points.

The pupils were studies on an individual basis. This involved observation in which the individual was observed in the context of a group and changes in the individual's disruptive behavior as he or she participates in different groups was documented. In the group observation each pupils was watched for the context under which these disruptive behaviors occur and this was does on a period of twenty " 20 " minutes. The observation took place in the classroom activities and also outdoor activities such as when they were in the playground.

Each of the two raters rated the context under which these disruptive behaviors occur using a four-point scale for every child. The data collected was analyzed using Cronbach Alpha reliability technique in ascertaining the internal consistency of the instrument. From the result alpha efficient value of 0.89 was obtained from the instrument. The children behavioral rating scale was face validated by three experts, two in Educational Psychology in the Department of Education Foundations and two experts of the Department of Psychology and one from science education department all in the University of Nigeria, Nsukka validated the instrument. Following the series of validation made, some modifications of the instrument were made. Mean on the four-point scale was used. A mean of 2.50 and above was recorded "occurs frequently", while a mean below 2.50 was recorded as "occurs slightly".

\section{Results and Discussion}

Table 1. Mean scores of the contexts of disruptive behaviors among pre-primary and primary school pupils

\begin{tabular}{ccccc}
\hline s/no & Contexts & Pre-primary (Mean) & Primary (Mean) & Grand mean \\
\hline 1 & When the child lacks writing materials & 2.66 & 3.06 & 2.86 \\
2 & When the child is oppressed by his/her classmates & 2.50 & 2.97 & 2.73 \\
3 & When the child lacks communication & 3.31 & 1.87 & 2.59 \\
4 & When the environment is noisy & 1.35 & 2.35 & 1.85 \\
\hline
\end{tabular}


Table 1 showed the contexts under which disruptive behavior occur. It was observed that context such as items 1, 2, 3 and 5 which are lack of writing materials, when the child is oppressed by other class mates, lack of communication and when the child is frustrated are the contexts under which disruptive behaviors occur frequently. These are for preprimary school pupils. On the other hand, item 4, which is when the environment is noisy is the only context under which disruptive behaviors occur slightly. This could be because most of the schools were situated along the major roads in the Nsukka urban whereby traffic noise is a usual aspect of life in this area. Beside, two of the schools under study is situated beside a filling station whereby cosines who come to patronize the owner of the fuel station

For the primary school pupils, the context under which disruptive behaviors frequently occur were items, 1 and 2 which are lack of writing materials and always. Therefore, the children might have been used to the noisy environmental population when the child is oppressed, while these behaviors slightly occurred on items 3, 4 and 5 which are when the child lacks communication, when the environment is noisy and when the child is frustrated respectively. For both pre-primary and primary school pupils. The average mean indicated that disruptive behaviors occur frequently on four (4) out of the five (5) items. These items are items 1, 2, 3, and 5 while item 4 occurred slightly. The indication is that these disruptive behaviors occur among pre-primary and primary school pupils under the stated contexts.

Table 2. Mean scores of the contexts of disruptive behaviors based on gender

\begin{tabular}{cllcc}
\hline S/no & \multicolumn{1}{c}{ Contexts } & Pre-primary Mean score (Male) & Primary Mean score (Female) & Grand mean \\
\hline 1 & When the child lacks writing materials & 3.10 & 3.18 & 3.14 \\
2 & When the child is oppressed by his/her classmates & 2.68 & 2.77 & 2.72 \\
3 & When the child lacks communication & 2.80 & 2.12 & 2.46 \\
4 & When the environment is noisy & 2.79 & 2.70 & 2.63 \\
\hline
\end{tabular}

Table 2 shows the mean overall scores of the two groups (male and female) as observed by the researchers. It was observed that in both groups' items 1,2, 4 and 5 occur frequently while item 3 occurs slightly. The table also indicates the five contexts under which disruptive behaviors manifested based on gender (male and female). For male they manifested under the five contexts with mean scores above 2.50. For female, the disruptive behaviors frequently occur under 4 out of the 5 contexts, excluding when the environment is noisy which is item 4 as indicated on the table which occurred slightly. The Grand Mean results indicated that out of the five items, only one shows a Mean below 2.50 showing that disruptive behaviors occurs slightly with this item.

The results indicate the contexts under which disruptive behaviors were displayed. There are evidences that both pre-primary and primary school pupils displayed disruptive behaviors in the highest order "when they lack writing materials". In this context, such pupils think they are free to play about and disturb others. This implies that writing materials is very relevant for pupils, in order to minimize their disruptive behavior. It has been observed that the early childhood deprivation like lack of adequate parental care results in a retarded rate of development (Mangal, 2010). This might lead to lack of psychological maturation. This implies that the failure of parental cooperation, by not providing writing materials, has adverse psychological effect on children and definitely will lead to the manifestation of disruptive behaviors. This is because this lack of writing materials tends to retard both academic and the psychological well being of the children who have already been labeled as disruptive children among their class mates. Psychologically, this can account for the feeling of inferiority complex. The possibility of this manifesting in adulthood is not ruled out. Myer (2000), and Mangal (2010) noted that, some parents demand behaviors and academic achievement beyond the ability of the children whom they have always snubbed by not preparing them appropriately as required from caring parents. Psychologically, this tends to demoralize the children who have no alternative then to keep themselves busy by disrupting the other classmates, the teachers and themselves. At the end these children might end up not building up their self-confidence and self-concept. Researchers agreed that it is the interaction of individuals' psychological self that determines the psychological adjustment required for appropriate well being. Other contexts in which disruptive behaviors were very common 
among the pupils, in their descending order were as follow;

- When the child is oppressed by his classmates. He reacts to this oppression by creating disruptive behavior, which could come in form of crying, shouting and struggling. The implication of these reactions probably is to draw the attention of the teachers, in order to be attended to.

- When the child is frustrated, the child also reacts to frustration by fighting, pushing, or withdrawing. This is in line with the view of Drummond (2000) that the responses to frustration include withdrawal and regression. In effect if a child is unable to vary his responses to a frustrating situation so that his needs become satisfied in a socially acceptable manner, the child will become disruptive in one way or the other Ikediasi and Akande, (2015). This implies that when a child is frustrated it has affected the psychology of the child, and appropriate concentration becomes difficult and this will definitely influence the academic achievement of the child.

- When the child lacks communication, it leads to undesirable responses and also increases the chance of blocking messages which the teacher wants to convey and therefore creates disruptive behaviors on both the teacher and the learners.

When referring to the contexts of disruptive behavior in pre-primary schools, there are some differences between the mean of the two groups. Pre-primary school pupils particularly tend to display disruptive behaviors as the result of "lack of appropriate communication" between the teaching aid and the pupils. This was what happened during the researchers' observational study. On one of the occasions, a teacher in one of the pre-primary schools had to slot in a video tape and the pupils were left on their own, but unfortunately they could not understand the language and actions in the film they were watching and this created a lot of disruptive behaviors among the pupils. Many were moving about while others were playing. This is in line with Akubue (1991), Mangal (2010), and Allen and Heinns (2002) argument that some illustrations of teachers can cause "communication gap" unless these are made intelligible to the young minds that may not be familiar with them. In line with this finding, Shaffer and Kipp (2007) observed that children process program content in a piece meal fashion, but are more likely to be captivated by zooms, cuts, loud music and cartoon voices. According to Ajibola and Ali (2014) they often direct their attention elsewhere during slower and quiet dialogue.

The results also show that pre-primary school pupils generally displayed more disruptive behavior than primary school pupils as a result of their immature age. Specifically, primary school pupils displayed more disruptive behaviors when they lack writing materials, and when their classmates oppress them. This is in line with Lindgren (1986), Onwuasoanya (2006), Mangal (2009), and Ogunjimi, Salami, and Oyedare (2015) who observed that disruptive behaviors are displayed as a result of reciprocal. Above all, when the contexts in which disruptive behaviors manifested are properly addressed, the children under these situations will completely get to adjust to the rules and regulations involved in the classroom situation.

\section{Conclusion}

This study examined the context by which disruptive behaviors were exhibited among Pre-primary and primary school pupils. The study also emphasized on the psychological. Implications were addressed. Two purposes and two research questions guided the study.

The study revealed that the pupils manifested disruptive behaviors under the following contexts:

When the children lack writing materials, when the children are oppressed, when the environment is noisy, and when they are frustrated. Both pre-primary and primary school children pre-primary and primary school pupils manifested disruptive behaviors on four out of the five items. The outstanding one is when the children lack communication. It could be that they got confused; wondering what was going on in the classroom, probably trying to understand the situation at that moment.

Generally, there were some indications, which certain behaviors were dominated among pre-primary and primary school pupils. This implies, that disruptive behaviors can manifest in children even at pre-primary school level. Psychologically, this behavior could affect the self-esteem of the children in future. This is in line with some researchers' findings that individual's adult life and personality are much influenced by his early life experiences (Mangal, 2010; Myer, 2002; Onwuasoanya, 2007). The implication is based on the fact that at childhood stage, children are beginning to incorporate and adjust to a sense of right and wrong with their psychological makeup or mind set they may do things that appear to be disruptive but which really reflect that they are victims of their psychological developmental age or level. This is in agreement with Hurlock (1982), who noted that children react according to their level of psychological development. This implies that psychologically, as children develop, the tendency to reduce the manifestation of these disruptive behaviors is possible. As they mature their mind set tends to change and disruptive behaviors are less expressed due to the fact that they learn how teachers and their 
classmates feel about their disruptive behaviors.

\section{References}

Ajibola, A., \& Ali, A. H. (2014). Disciplinary measures in Nigerian secondary schools: Issues and prospects. Journal of research and method in Education, 4(3), 11-17.

Akubue, A. U. (1991). Classroom Organization and Management. In A5-Point Strategy. Owerri Wisdom Publishers Ltd.

Ali, A., \& Gracey, D. (2013). Dealing with students disruptive behaviour of post graduate students. A case study of Stafford University United Kingdom Journal of research and method education, 3(6), 39-43.

Allen, R. S., \& Heinns, M. M. (2002). Employee perceptions of the relationship between strategy, Rewards and Organizational Performance. Journal of Busienss Strategies, 2, 115-139.

Balley, R. K., \& Owens, D. L. (2005). Overcoming challenges in the diagnosis and treatment of attention deficit/hyperactivity disorder in Africans Americans. Journal of National Medical Association, 97, 55-105.

Bandura, A. (1977). Social learning theory Englewood Cliffs. N.J. Prentice-Hall.

Bandura, A. (1989). Social cognitive theory. In R. Vista (Ed.), Annals of Child Development (pp. 1-60).

Cooper, C. G. (1987). The development and validation of an inveritory to detect emotional stress in children. Dissertation Abstracts International. The humanities and Social Science, 47, 83-85.

Coplan, R. J., Gauinski-Molins, M., Lagace-Dequin, D. G., \& Wichman, C. (2001). When girls versus boys play alone. Nonsocial play and adjustment in kindergarten developmental psychology, 27, 464-474.

Davey, G. (2011). Psychopathology. In Research, assessment, and treatment in clinical psychology. Chichester, Wiley.

Drummond, H. (2000). Introduction to organizational behaviour. Oxford University Press.

Dunn, J., \& Hughes, C. (2001). "I got some swords and you're dead" Violent fantancy anti-social behaviour, friendship, and moral sensibility in young children. Child Development, 72, 491-505. https://doi.org/10.1111/1467-8624.00292

Edovald, T. (2001). Definitional and classification issues in antisocial behaviour. University of Oxford: Department of social policy and social work.

Hurlock, E. B. (1982). Child growth and development (6th ed.). McGraw.

Ifekwunigwe, M. (2004). Perceptions of stress in elementary school children. The Humanities and Social Sciences, $46,202-224$.

Ikediasi, N. N., \& Akande, J. A. (2015). Antisocial behaviour among Nigerian adolescents. Journal of research and method in education, 5(4), 31-36.

Krejcie, R. V., \& Morgan, D. W. (1970). Determining sample search for Research. Educational and Psychological Measurement, 30, 607-610. https://doi.org/10.1177/001316447003000308

Lemieux, R. E. (1985). The study of the adaptation of Hmong first, second and third graders to the Minneapolis and public schools. The Humanities and Social Sciences, 46, 115-129.

Lingren, H. C. (1976). Educational psychology in classroom (5th ed.). Sir Francisca State University, John Wiley and son.

Mangal, S. K. (2010). Advance educational psychology (2nd ed.). New Delhi, PHL, Learning Private Limited.

Mangal, S. K. (2011). Essential of Education Psychology. New Delhi, PHL, Learning Private Limited.

Myer, D. G. (2002). Exploring psychology (5th ed.). New York: Worth Publishers.

Nelson, J. (2011). Positive discipline. Random House Publishing Group, New York, USA.

Nworgu, B. G. (2015). Educational Research. In Basic issues and methodology. Ibadan: Wisdom Publishers Ltd.

Ofordile, C. (2002). Behaviour modification; principles and application. Enugu; Tinkers Corner.

Ogunjini, O., Salami, T., \& Oyedare, O. (2015). Parents and students' interest as determinates of students' academic performance in Agricultural science in selected secondary school in Oyo Metropolis, Oyo State. International Journal of Academic Research in Progressive Education and Development, 4(4), 11-20.

Onwuasoanya, P. N. (2006). Behaviour modification techniques in counseling. Nsukka: Great AP Express 
Publishers.

Punch, K. F. (2011). Introduction to research method in education. London SAGE Publication Ltd.

Ramalingam, P. (2006). Academics dictionary of psychology. New Delhi: Academic Publishers.

Rosenbery, M. (2005). Society and adolescent self-image. Princeton University Press, Princeton, USA.

Schostak, J. C. (1983). Maladjusted schooling. London, Falmer.

Shaffter, D. K., \& Kipp, K. (2007). Developmental Psychology: Childhood and adolescence. Retrieved from http://2017StudyMode.com

Stark, R. L. (2006). The effect of family conflict on school behaviours as perceived by children and teachers. The Humanities and Social Sciences, 47, 145-160.

Stott, D. H. (1982). Helping the maladjusted child. Milyon Keyness, Open University Press.

\section{Copyrights}

Copyright for this article is retained by the author(s), with first publication rights granted to the journal.

This is an open-access article distributed under the terms and conditions of the Creative Commons Attribution license (http://creativecommons.org/licenses/by/4.0/). 